\title{
Editorial to: "Transoral resection of large parapharyngeal space tumors" by Hussain et al.
}

\author{
O. Guntinas-Lichius
}

Received: 24 April 2013/Accepted: 29 April 2013/Published online: 4 May 2013

(C) Springer-Verlag Berlin Heidelberg 2013

The parapharyngeal space is not easily accessible for routine clinical examinations and remains silent until affected by pathological processes like tumors [3]. Parapharyngeal space tumors are rare, most are benign. Next to typical salivary gland tumors, the parapharyngeal space can house a variety of even rarer tumors [4]. Imaging studies are essential to get more information on the location (pre- or post-styloid space) and the extent [6]. In general, magnetic resonance imaging (MRI) with gadolinium is the preferred imaging study for parapharyngeal space neoplasms. In addition, fine-needle aspiration cytology can be useful [10]. In contrast, open biopsy can be hazardous because of the risk of injury to large vessels and cranial nerves in the parapharyngeal space. In case of a pleomorphic adenoma, a preceding biopsy could create adhesions between the tumor and the surrounding tissue making it problematic to remove the neoplasm via blunt dissection what is particularly important for pleomorphic adenoma [4]. Furthermore, a biopsy would per se increase the risk of tumor recurrence. A comprehensive diagnostic work-up is very important because many tumors are benign and slowly growing, often asymptomatic, i.e. there is often no urgency of treatment [4].

The colleagues from the Department of OtolaryngologyHead and Neck surgery in Aberdeen, Scotland, present a case report of their experience with transoral resection of five parapharyngeal space tumors. Due to the small sample size, all conclusions drawn by the author can only regarded as preliminary. Furthermore, the follow-up of the patients

O. Guntinas-Lichius $(\bowtie)$

Department of Otorhinolaryngology, Jena University

Hospital, Jena, Germany

e-mail: Orlando.Guntinas@med.uni-jena.de with a pleomorphic adenoma is too short to draw any conclusion concerning the risk of tumor recurrence.

One patient did not receive any preoperative imaging but a preoperative biopsy. Three patients received preoperative fine-needle aspiration cytology and an MRI examination. And the last patients received a computed tomography (CT) scan preoperatively but no other specific preoperative diagnostics. The aim of the presented prospective investigation was to evaluate a surgical technique. Therefore, from a methodological perspective, it would have been advantageous to use a standardized and established preoperative work-up. Unfortunately, this was not done. The result was that in two patients (cases 1 and 5) a preoperative biopsy was taken although these patients could have had (but fortunately did not as revealed by final histology) a pleomorphic adenoma or, for instance, a sarcoma. In both situations, a biopsy would have been hazardous or even contraindicated!

The transcervical approach and the transcervical-parotid approach are the most commonly used surgical approach to the parapharyngeal space [4, 9]. Probably, it would have been possible to resect all five cases using one of the standard approaches. It is very important to emphasize that a transoral removal, i.e. the approach used in the presented study, is associated with an unacceptably high rate of tumor rupture and recurrence for pleomorphic adenomas of the parapharyngeal space managed by transoral removal $[1,2,4,5,8]$. Moreover, it is difficult to follow the terminology used by Hussain et al. to describe their transoral approach: the authors describe the technique with the term "extracapsular dissection" although some tumors were resected with piecemeal technique or cored out with an ultrasonic aspirator or with a microdebrider. De facto, a piecemeal technique or coring out a tumor should be named "intracapsular enucleation" [11] and some of the 
intraoperative photographs the authors show correspond to an "extracapsular enucleation". Both approaches are, to the present state of knowledge, contraindicated for pleomorphic adenomas because of the high risk of recurrence. In contrast, "extracapsular dissection" is defined as resection of a salivary gland tumor with adjacent normal salivary gland tissue without exposure of the facial nerve $[7,11]$. Extracapsular dissection is nowadays accepted as minimal margin surgery for small and mobile tumors of the lateral parotid lobe. So far, extracapsular dissection has not been established as a standard procedure for deep lobe tumors or parapharyngeal space tumors even using a standard transcervical approach.

In conclusion, the methodological limitations and the small sample size of the study of Hussain et al. do not allow drawing any final conclusions on the value of the presented surgical technique. It should only performed in clinical studies with better study design and better definition of the surgical technique.

\section{References}

1. Allison RS, Van Der Waal I, Snow GB (1989) Parapharyngeal tumours: a review of 23 cases. Clin Otolaryngol All Sci 14:199-203
2. Betka J, Chovanec M, Klozar J et al (2010) Transoral and combined transoral-transcervical approach in the surgery of parapharyngeal tumors. Eur Arch Otorhinolaryngol 267:765-772

3. Bradley PJ, Guntinas-Lichius O (2011) Salivary gland disorders and diseases: diagnosis and management. Thieme, Stuttgart

4. Eisele DW, Richmon JD (2013) Contemporary evaluation and management of parapharyngeal space neoplasms. J Laryngol Otol: 1-6. [Epub ahead of print]

5. Goodwin WJ Jr, Chandler JR (1988) Transoral excision of lateral parapharyngeal space tumors presenting intraorally. Laryngoscope 98:266-269

6. Gupta A, Chazen JL, Phillips CD (2012) Imaging evaluation of the parapharyngeal space. Otolaryngol Clin North Am 45:1223-1232

7. Klintworth N, Zenk J, Koch M et al (2010) Postoperative complications after extracapsular dissection of benign parotid lesions with particular reference to facial nerve function. Laryngoscope 120:484-490

8. Lau WF, Lam KH, Wei W (1986) Parapharyngeal space tumours. Aus N Zea J Surg 56:835-842

9. Malone JP, Agrawal A, Schuller DE (2001) Safety and efficacy of transcervical resection of parapharyngeal space neoplasms. Ann Otol Rhinol Laryngol 110:1093-1098

10. Oliai BR, Sheth S, Burroughs FH et al (2005) "Parapharyngeal space" tumors: a cytopathological study of 24 cases on fineneedle aspiration. Diagn Cytopathol 32:11-15

11. Zbaren P, Vander Poorten V, Witt RL et al (2013) Pleomorphic adenoma of the parotid: formal parotidectomy or limited surgery? Am J Surg 205:109-118 